\title{
Adverse effects of medicinal plants used by cancer patients in Beni Mellal and the communication of this use
}

\author{
Mohamed Aboufaras ${ }^{1,2}$, Karima Selmaoui ${ }^{1}$ and Nadia Ouzennou ${ }^{3}$ \\ ${ }^{1}$ Faculty of Sciences, Ibn Tofail University, University Campus, BP 242, Kenitra, Morocco \\ ${ }^{2}$ Higher Institute of Nursing and Technical Professions (ISPITS), Regional Hospital Center - district Dchira, Béni Mellal, Morocco \\ ${ }^{3}$ Higher Institute of Nursing and Technical Professions (ISPITS), Gueliz Headquarters, Marrakech, Morocco
}

\begin{abstract}
Moroccan cancer patients use traditional herbal medicine and no ethno botanical study has targeted them in the Béni Mellal Khénifra region. We had the objective to measure the frequency use of medicinal plants by cancer patients in the region of Béni Mellal Khénifra as well as the communication around this use and to inventory the plants used added to their adverse effects. We used an ethno botanical survey was conducted among 314 patients at the regional oncology center of Béni Mellal. The prevalence of use and the relative frequency of citation (RFC), the proportion of patients reporting this use and its adverse effects were measured. the prevalence of medicinal herbs use was $37.3 \%(\mathrm{n}=117)$. The citation relative frequency of plants ranged from 0.005 to 0.16 . We found, also, 32 species belonging to 19 botanical families. Almost $90 \%$ $(\mathrm{n}=102)$ of patients do not communicate this use and the most used plants are: Marrubium vulgare $(16 \%)$, Ephedra alata (13\%) and Juniperus oxycedrus (12\%) Some plants seem toxic, in particular Juniperus oxycedrus used in a form of tar. The drug-plant interaction requires monitoring due to the lack of communication.
\end{abstract}

Keywords: Cancer, phytotherapy, Adverse effects, Communication

\section{Introduction}

About 70 to $80 \%$ of patients in Africa are treated with traditional medicine (TM) due to the high costs of conventional medicines, their natural origins [1] as well as their availability [2].

In Morocco, traditional medicine, especially plants, were widely used by folk medicine to treat ailments and diseases, and they are still used in the same way especially in rural areas $[3,4]$. Several ethnobotanical studies have shown that between 55 and $90 \%$ of the general population use medicinal plants [5].

Cancer patients similarly to the others tend to frequently use all types of traditional and complementary medicine more than healthy people [6,7]. Indeed, having cancer triples the chance of using these medications [8].

Cancer is a devastating disease that is considered to be one of the greatest challenges to human health around the world[9]. By 2030, the estimated number of new cancer cases worldwide is around 21.4 million, while the number of deaths is estimated to be 12.4 million[9]. In Morocco, tumors represented $13 \%$ of death cases in this country in 2015 (Ministry of Health Morocco Health 2016).

Current cancer therapies are associated with high systemic toxicity, limiting their tolerance and clinical application, This situation is further complicated in developing countries such as Morocco since only $26 \%$ of these countries reported having services available for this pathology in the public sector [10]. This context leads patients to resort to traditional therapies.

In Morocco, the studies related to traditional medicine (TM) in cancer patients are not numerous. In fact, Tazi et al. who studied the prevalence of this use in patients with malignant haematological tumors in Marrakech found that $68 \%$ of these patients used at least a modality of TM / MAC after cancer diagnosis. Also, $65 \%$ of them have used techniques whereas $72 \%$ deal with substances[11].

Chebat et al. assessed the prevalence of adverse effects linked to medicinal plants use in this center. They found after a survey of 1234 patients consulting or under treatment in the chemotherapy department that $35 \%$ of them use herbal remedies for permanently treating cancer. The results of this study showed that $16 \%$ of the $98.5 \%$ of users that do not disclose the information to their doctor have more or less serious side effects. Actually, Tubulointerstitial nephritis, the most common undesirable effect, represents $15.7 \%$ followed by liver damage with $12.9 \%$, diarrhea with $5.7 \%$, vomiting, constipation and rectal bleeding all with $4.3 \%$ each [12].

These adverse effects could be the consequence of pharmacodynamic or pharmacokinetic interactions with chemotherapy [13]. Direct and also possible toxicity (anaphylaxis, hepatic toxicity, renal failure, cardiovascular toxicity, carcinogen, etc.) $[13,14]$, herbal preparations can also complicate surgery if taken before lumpectomy, their consumption could have a serious effect by increasing the risk of bleeding[14]. In addition to these direct risks and drug interactions, there is a

\footnotetext{
* Corresponding author: mohamed.aboufaras@uit.ac.ma
} 
indirect risk, in reality, a herbal remedy may delay or replace an effective form of conventional treatment [15].

It is clear that the toxicity of herbal therapy is a major public health problem as it is an undeniable reason for hospitalization, In fact, and according to a large international meta-analysis including 69 countries and 419,000 patients, the proportion of hospitalized patients with adverse events in herbal medicine was 6.7\% [16]. Another study showed an interaction rate of $8 \%$ between plants and oral chemotherapy [17].

In the Middle East and North Africa region (MENA) and under-developed countries where unstandardized herbal preparations are widely used, we cannot predict these potential adverse effects, since the composition and quality of these preparations depends on the part used (leaf, seed, root), their harvests, the use of pesticides, the diversity of the climate and soil where they are raised, and the storage conditions [18] especially since the skills of the people who sell these plants (Âaraga, Âchaba and Âatara) are inappropriate because anyone who can open a shop and present herbal medicine substances, these healers use different dosages, for example, the number of plant leaves in a teapot of boiling water varies from one herbalist to another [19].

In Morocco, although ethnobotanical investigations carried out in the central Middle Atlas revealed that several medicinal plants were declared toxic by the practitioners of traditional medicine surveyed [20].

Thus, the Moroccan anti poison center declared that medicinal plants were responsible for $3.3 \%$ to $5 \%$ of intoxication cases and that the region of Béni Mellal is ranked second after Casablanca in all poisonings (CAPM - Center Anti-Poison from Morocco, 2009;). Since no ethnobotanical study has been concerned with cancer patients in the region, our objective was to measure the frequency of medicinal plants use by cancer patients in the Beni Mellal Khénifra region, the communication around it and to make an inventory of the plants used and also their undesirable effects.

\section{Methods}

\subsection{Region and location of the study}

The Beni Mellal khénifra region is a new Moroccan region created according to the new administrative division of 2015 encompassing five provinces: Azilal, Béni Mellal, Fquih Ben Salah, Khénifra and Khouribga (figure 1). It is located in the area of Atlas Mountains and Tadla Plain, especially in the center. It is an ArabAmazigh region housing a new regional oncology center inaugurated in 2019.

With the presence of plains and mountains (Eastern High Atlas and central Middle Atlas), as well as various natural sites and natural resources such as the Ouzoud waterfalls, Ain Assedoune's sources, and Oued Oum ErRbia, this region's natural heritage (hydraulic and forestry) is rich and diverse.. This region's natural resource diversity and richness provide forestry potential, which contributes to the socio-economic development of inhabitants by supplying wood, days of employment, breeding routes, and plants, among other.

\subsection{Study design and measures}

This is both an epidemiological study of the medicinal herbs prevalence use and an ethnobotanical survey aimed at listing these herbs, their effects perceived by patients as well as the communication of the caregiver around this utilization. This study was conducted on 314 patients at the regional oncology center of Béni Mellal between the months of June 2020 and February 2021. We proceeded by quota sampling according to sex and cancer type.

This research included adults with cancer of any type. The data collected were of a socio-demographic (sex, age, age, sex, ethnicity, province and place of residence, level of education, type of family, monthly family income), clinical aspect (Type and duration of cancer, type of treatment received) and involved information about using medicinal plants:

- The plants used

- The method of preparation

- The method of preparation and the duration of this use.

- Dosage.

- The frequency of use

- The moment of use compared to anticancer treatments

- Undesirable effects of this use.

- The reasons for using medicinal plants

- The communication of this use

The prevalence of use and the relative frequency of citation (RFC), the proportion of patients reporting this use and the adverse effects of this use were measured.

\section{Results and Discussion}

\subsection{Characteristics of the participants}

The sample of 314 patients had an average age of 54 years, they came from an urban environment (47.5\%), predominantly female $(74.8 \%)$, illiterate $(72.3 \%)$, married (70\%), of Arabic-speaking origin (76\%), low monthly family income $(69.7 \%)$ and without professional activity $(72 \%)$. Based on the clinical profile of participants, the majority had breast cancer (42\%), followed by cervical cancer $(12 \%)$ and colorectal cancer (11\%). Two-thirds of the patients had a cancer duration of less than 12 months. Most of the respondents ( $75 \%$ ) had received at least one chemotherapy session.

\subsection{Frequency and patterns of use}

The prevalence of patients who used herbal remedies was $37.3 \%(n=117)$. More than half of the participants considered these herbs to permanently treat cancer, while the remaining had the intention to improve their quality of life. These results are very close to the prevalence found in other regions of Morocco, In fact, 35\% of patients in Rabatuse medicinal plants to treat cancer [6]. 
Kabbaj et al. Found the same results at the same oncology institute in 691 patients, they pointed out that $39 \%$ of patients interviewed regularly used medicinal plants simultaneously with medical treatment [21].

The same results were found in Marrakech, a study of MAC in 384 patients found a prevalence of $71 \%$ of use of these therapies. The majority used spiritual practices, followed by plants with a prevalence of $26 \%$ [22].

These outcomes are near the utilization of modern natural medication in North America, subsequently, among the $83.3 \%$ of clients of Complementary and Alternative Medicine (CAM) in the United States of America, 38.\% utilized plants.[23]. The predominance of the use of plants has also been observed in Trinidad and Tobago. Indeed, the prevalence of CAM use was 39.1\%, and plants represented $94.2 \%$ among these CAMs used [24].

Then again, in Europe, a study made it conceivable to straightforwardly contemplate the predominance of the utilization of phytotherapy by cancer patients in the United Kingdom. It's anything but a lower commonness contrasted with Morocco, it changed somewhere in the range of 3.1 and $21.8 \%$ in adults, and somewhere in the range of 4.1 and $20 \%$ in pediatric oncology examines [25].

In the Middle East and North Africa (MENA)Region. The utilization of plant preparations is exceptionally far reaching and basically indistinguishable from that of in Morocco, indeed, among the 1138 Jordanian patients met, 404 revealed having utilized plants, which gives a pervasiveness of $35.5 \%$. $66 \%$ of these patients utilized crude plant separates while getting ready them as an implantation, and just $6.8 \%$ utilized all around dosed and normalized home grown items (garlic tablets)[26].

Our findings allowed us to identify 32 species of plants used by these patients. The Relative Citation Frequency (RFC) ranged from 0.005 to 0.16 . The three most used plants are Marrubium vulgare (16\%), Ephedra alata $(13 \%)$ and Juniperus oxycedrus $(12 \%)$ added to Nigella sativa $(6 \%)$. The most represented families are Lamiaceae with 7 plants and Apiaceae with 4 plants.

Compared to these families identified in our research, the same results have been in broad literature review in Morocco. The predominant families were Lamiaceae (11 species), followed by Apiaceae and Fabaceae (9 species)[27]. These recent results confirm those found in previous studies[3].

About the species found, these results are specific to the Beni Mellal khénifra region since a recent Moroccan ethnopharmacological review identified 103 species of plants belonging to 47 botanical families used by Moroccans to treat cancer. Among them, 48 species have traditionally been used as anticancer drugs, while the rest have been tested by experimental studies. Aristolochia fontanesii Boiss. \& Reut, Marrubium vulgare and Allium sativum were most frequently used. This study, which was conducted by analyzing 22 ethnobotnaic surveys from 1991 to 2019 [27].

The results of these studies showed that the Aristolochiaceae family ( Aristolochia longa,
Aristolochiaboetica), braztam in Moroccan dialect,Chajarat Rustin Arabic, has been frequently used in most of these studies [1,21,22,28,29]. This plant took second place in two other studies at the national institute of oncology in rabat. The frequency of use was $33 \%$ in 2011 and $29.7 \%$ in 2013 [12,30]. On the other hand, in our study, this plant only occupied tenth place with only $6 \%$ of users.

Cancer patients in our study sometimes used more than one plant simultaneously or sequentially with conventional medical treatment (Figure 1) with a duration of use ranging from 2 days to over a year. A third of users have utilized the infusion mode for the preparation of these plants and $86 \%$ have not communicated this use with the healthcare team.

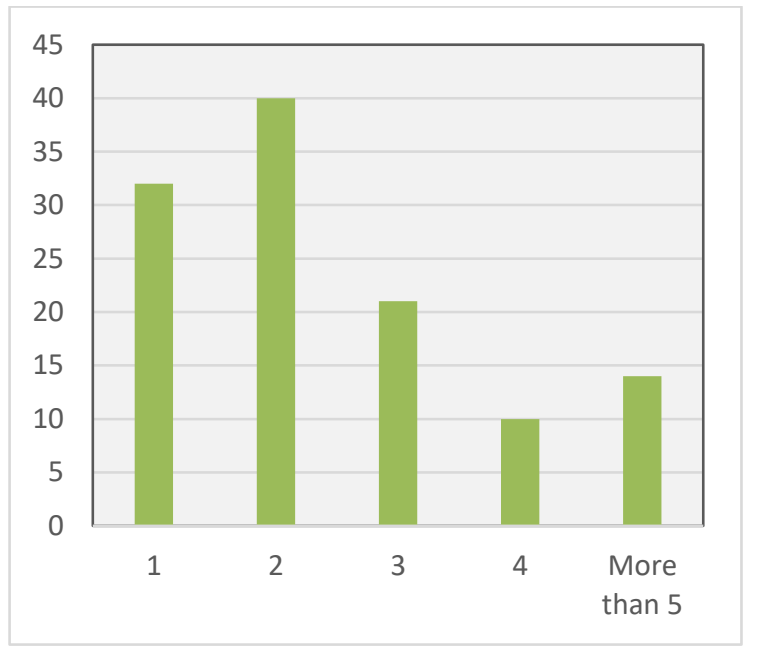

Fig 1: Number of plants used per patient

\subsection{Adverse effects of the plants used}

$18 \%(\mathrm{n}=22)$ of users reported having side effects following the use of medicinal plants. Women were most affected by these effects $(n=17)$, including women with breast cancer $(n=10)$, followed by patients with lung cancer $(n=3)$.

Juniperus oxycedrus L. was the most implicated with six citations noting digestive disturbances (gastralgia; vomiting; diarrhea) and nephro-toxicity. Some toxic effects felt and declared are summarized in Figure 1.

These results are close to those of Chabat à rabat team showing that $16 \%$ of plants users at the level of rabat INO (institute national d'oncologie in Rabat) developed adverse effects. But this large-scale study did not mention the use of Juniperus oxycedrus L., nor of course the adverse effects that result.

These findings also agree with the figures of the Moroccan poison control and pharmacovigilance center which report a high frequency of poisoning plant cases despite the provisions of the Dahir law of February 27, 1923 prohibiting the retail sale of poisonous plants by herbalists (Bulletin Official, 1923)[31]. It is important to add that poor communication is also worrying and requires special attention [32].Patients stated that they did not communicate this use as physicians did not request or 
fear being deprived of chemotherapy and treatment at the oncology centre.

This lack of dialogue could be due either to the noninitiation of communication about the subject by the caregivers, to the non-perception of the potential risk of the substance used concomitantly with anticancer drugs, to the lack of confidence in the caregivers. , fear of reprimand, and the perception of patients that their treating physicians lack knowledge about TM / MAC $[26,33]$.

Table 1: Some side effects of medicinal plants

\begin{tabular}{|l|l|l|}
\hline Herbs & Side effects & $\begin{array}{l}\text { Number } \\
\text { of } \\
\text { citation }\end{array}$ \\
\hline $\begin{array}{l}\text { Juniperus } \\
\text { oxycedrus L. }\end{array}$ & $\begin{array}{l}\text { Digestive } \\
\text { disorders and } \\
\text { nephro-toxicity }\end{array}$ & 6 \\
\hline Artemisia vulgaris/ & liver toxicity & 3 \\
\hline $\begin{array}{l}\text { Foeniculum } \\
\text { vulgare/Pimpinella } \\
\text { anisum }\end{array}$ & liver toxicity & 1 \\
\hline Marribium Vulgare & $\begin{array}{l}\text { digestive } \\
\text { disorders }\end{array}$ & 2 \\
\hline $\begin{array}{l}\text { Euphorbia echinus } \\
\text { Coss. \& Hook }\end{array}$ & dizziness & 1 \\
\hline
\end{tabular}

This lack of knowledge requires special attention [32] because the majority of caregivers feel unable to give information or advice regarding the efficacy and safety of TM / MAC or herbal remedies in particular [34,35]. Indeed, only $3 \%$ of doctors, pharmacists and nurses believe that they have appropriate information to give to their patients regarding alternative medicine [36]. This lack is considered a very serious challenge in communication or medical practice since it could be frustrating for the caregiver who feels helpless and the caregiver who perceives his caregiver as indifferent or having a negative attitude [37].

This practice (therapeutic education) based on scientific evidence would encourage healthcare professionals in oncology to initiate a discussion about the different modalities of MT / MAC with patients and in particular herbal medicine [38]. Maintaining good communication is essential. This is because interactions that patients perceive as incomplete or indifferent create the type of frustration and dissatisfaction and likely contribute to adverse events, patient decisions to discontinue conventional care, or too frequent complaints about cancer medicine [39].

It is imperative to ask patients if they are taking any herbal products, especially when they have an unexplained medical condition. Clinicians should be made aware of the potential effects of herbal preparations and should be able to discuss this topic without being judgmental. They must draw a line between a seemingly sympathetic position that could be interpreted as approval of unproven therapies and final disapproval, which would discourage patients from disclosing their use of herbal remedies [15].

\section{Conclusion}

The use of medicinal plants in the region of Beni-Mellal khenifra is quite frequent as well as the undesirable effects that follow. $18 \%$ of patients at the Beni Mellal Oncology Center had an adverse reaction to mons following the use of traditional botanical preparations. The plants used in this region are different from those used in Rabat or Casablanca compared to the species used, however, the botanical families used are identical to those found in previous studies. The lack of communication about this use could increase the frequency and severity of these undesirable effects. So, a phytovigilance system with staff training in this area seems to be essential.

\section{References}

1. M. Bourhia, A. A. Shahat, O. M. Almarfadi, F. A. Naser, W. M. Abdelmageed, A. Ait, H. Said, F. El Gueddari, A. Naamane, L. Benbacer, and N. Khlil, Evidence-Based Complement. Altern. Med. 2019, (2019)

2. A. D. Akyol and B. Öz, Complement. Ther. Clin. Pract. 17, 230 (2011)

3. J. M. Alves-Silva, A. Romane, T. Efferth, and L. Salgueiro, Front. Pharmacol. 8, 1 (2017)

4. A. Bouyahya, J. Abrini, A. Et-touys, Y. Bakri, and N. Dakka, Eur. J. Integr. Med. 13, 9 (2017)

5. H. Jouad, M. Haloui, H. Rhiouani, J. El Hilaly, and M. Eddouks, 77, 175 (2001)

6. B. Cassileth, K. S. Yeung, and J. Gubili, Complement. Altern. Ther. Oncol. 109 (2008)

7. J. M. Wilkinson and M. J. Stevens, 11, 139 (2014)

8. J. M. Fouladbakhsh, ProQuest Diss. Theses 153 p. (2006)

9. F. Bray, J. Ferlay, I. Soerjomataram, R. L. Siegel, L. A. Torre, and A. Jemal, CA. Cancer J. Clin. 68, 394 (2018)

10. WHO, Cancer 2018 (2018)

11. I. Tazi, H. Nafil, L. Mahmal, M. Harif, M. Khouchani, Z. Saadi, R. Belbaraka, A. Elomrani, and A. Tahri, Bull. La Soc. Pathol. Exot. 106, 278 (2013)

12. A. Chebat, S. Skalli, H. Errihani, L.

Boulaâmane, M. Mokrim, T. Mahfoud, R. Soulaymani, and A. Kahouadji, Phytotherapie 12, 25 (2014)

13. S. Träger, Rev. Des Mal. Respir. Actual. 9, 408 (2017)

14. S. Koçaşh, Z. Demircan, and Y. B. Universitesi, 14, 325 (2017)

15. A. G. M. PETER, New Engl. J. Med. Rev. 347, 2046 (2002)

16. K. Gromek and P. Simas, Int. J. Risk Saf. Med. 


\section{7, 55 (2015)}

17. A. L. Clairet, M. Boiteux, J. Elsa, M. Jeannin, B. Gérard, V. Nerich, and S. Limat, Med. Oncol. 1 (2019)

18. D. Arslan, D. Tural, and E. Akar, J. Palliat. Med. 16, 1466 (2013)

19. Jamal Bellakhdar, contribution à l'étude de la pharmacopée traditionnelle au maroc: la situation actuelle, les produits' les sources du savoir :Enquête Ethnopharmacologique de Terrain Réalisée de 1969 ù 1992, Metz, France (1997).

20. M. Najem, L. Bachri, E. H. Bouiamrine, J. Ibijbijen, and L. Nassiri, Ethnobot. Res. Appl. 19, (2020)

21. F. Z. Kabbaj, B. Meddah, Y. Cherrah, M. El, and A. Faouzi, Phytopharmacology 2, 243 (2012)

22. I. Tazi, H. Nafil, M. Sifesalam, M. Bouchtia, and L. Mahmal, J. Acupunct. Meridian Stud. 6, 67 (2013)

23. M. A. Richardson and S. E. Straus, 29, 531 (2002)

24. M. Bahall, BMC Complement. Altern. Med. 1 (2017)

25. C. Gratus, S. Damery, S. Wilson, S. Warmington, and P. Routledge, 831 (2009)

26. F. U. Afifi, M. Wazaify, M. Jabr, and E. Treish, Complement. Ther. Clin. Pract. 16, 208 (2010)

27. I. Alami Merrouni and M. Elachouri, J. Ethnopharmacol. 266, 113435 (2021)

28. S. A. Brahmi, Z. Benbrahim, M. Berraho, and C. Nejjari, Pan African Med. J. · (2011)

29. Y. Samouh, A. Lemrani, H. Mimouni, M. Jaoud, and A. Ait Haj Said, Phytopharmacology 8, 135 (2019)

30. L. Hessissen, M. Bhour, M. El Kababri, A. Kili, M. N. Nachef, M. Elkhorassani, and M. Khattab, J. Africain Du Cancer 3, 163 (2011)

31. A. Yamani, V. Bunel, C. Husson, C. Stévigny, P. Duez, M. Elachouri, and J. Nortier, J. Ethnopharmacol. (2015)

32. E. Ernst, Am. J. Med. 104, 170 (1998)

33. J. S. Yates, K. M. Mustian, G. R. Morrow, L. J. Gillies, D. Padmanaban, J. N. Atkins, B. Issell, J. J. Kirshner, and L. K. Colman, Support. Care Cancer 13, 806 (2005)

34. C. A. Buckner, R. M. Lafrenie, J. M. Caswell, and D. A. Want, 25, 275 (2018)

35. M. S. Ali-shtayeh, R. M. Jamous, N. M. Y. Salameh, R. M. Jamous, and A. M. A. Hamadeh, J. Ethnopharmacol. 187, 104 (2016)

36. M. J. Montbriand, Oncol. Nurs. Forum 31, 26 (2004)

37. M. Frenkel, M. D. A. Cancer, L. Cohen, M. D. A. Cancer, B. R. Cassileth, N. York, D. I. Abrams, S. Francisco, J. L. Capodice, N. York, K. S. Courneya, S. Hanser, B. College, D. Labriola, N. Natural, H. Specialty, C. Clinic, D. W. Wardell, H. Science, and S. Sagar, 7, 85 (2009)

38. B. R. CASSILETH and G. DENG, Oncologist 80 (2004) 